\title{
Optimizing Chest X-ray Indication in Blunt Trauma Patients using Clinical Criteria
}

\author{
${ }^{1}$ Luca GA Pivetta, ${ }^{2}$ José G Parreira, ${ }^{3}$ Cristiano Below, ${ }^{4}$ Giovanna Z Rondini \\ ${ }^{5}$ Jacqueline AG Perlingero, ${ }^{6}$ José C Assef
}

\begin{abstract}
Background: There is an excessive number of unnecessary chest X-rays (CXRs) in minor blunt trauma patients.

Objective: To identify, using routine clinical criteria, a subgroup of blunt trauma patients that do not require CXR for assessment.

Materials and methods: This was a retrospective analysis of trauma registry data collected over a 24-month period. Adult blunt trauma patients undergoing CXR on admission were analyzed. The following clinical criteria were assessed: Normal neurologic examination on admission (NNEx), hemodynamic stability (HS), normal physical examination of the chest on admission (NCEx), age $\leq 60$ years, and absence of distracting injuries (Abbreviated Injury Scale $>2$ in head, abdomen, and extremities). These clinical criteria were progressively merged to select a group with lowest risk of exhibiting abnormal CXR on admission.
\end{abstract}

Results: Out of 4,647 patients submitted to CXR on admission, $268(5.7 \%)$ had abnormal findings on scans. Of 2,897 patients admitted with NNEx, 116 (4.0\%) had abnormal CXR. Of 2,426 patients with NNEx and HS, 74 (3.0\%) had abnormal CXR. Of 1,698 patients with NNEx, HS, and NCEx, 24 (1.4\%) had abnormal CXR. Of 1,347 patients with NNEx, HS, NCEx, and age $<60$ years, 12 had thoracic injury $(0.9 \%$ of total individuals receiving $\mathrm{CXR}$ ). A total of 4 patients underwent chest drainage. Among 1,140 cases with all clinical criteria, 8 had confirmed thoracic injuries and 2 underwent chest drainage.

Conclusion: A subgroup of blunt trauma patients with low probability of exhibiting abnormalities on CXR at admission was identified. The need for CXR in this subgroup should be reviewed.

Keywords: Clinical protocols, Decision making, Emergency medical services, Multiple trauma, Practice guidelines as topic, Radiography, Thoracic.

\footnotetext{
${ }^{1}$ Resident, ${ }^{2}$ Assistant Professor, ${ }^{3,4}$ Student, ${ }^{5,6}$ Professor

${ }^{1}$ Department of Surgery, Irmandade da Santa Casa de Misericórdia de São Paulo, São Paulo, Brazil

${ }^{2,5,6}$ Department of Emergency Service, Irmandade da Santa Casa de Misericórdia de São Paulo, São Paulo, Brazil

${ }^{3}$ Department of Emergency Service, School of Medicine, Santa Casa de São Paulo School of Medical Sciences, São Paulo Brazil

${ }^{4}$ Department of Medicine, School of Medicine, Santa Casa de São Paulo School of Medical Sciences, São Paulo, Brazil

Corresponding Author: José G Parreira, Assistant Professor Department of Emergency Service, Irmandade da Santa Casa de Misericórdia de São Paulo, São Paulo, Brazil, Phone: +551121767264, e-mail: jgparreira@uol.com.br
}

How to cite this article: Pivetta LGA, Parreira JG, Below C, Rondini GZ, Perlingero JAG, Assef JC. Optimizing Chest X-ray Indication in Blunt Trauma Patients using Clinical Criteria. Panam J Trauma Crit Care Emerg Surg 2017;6(1):30-34.

Source of support: Nil

Conflict of interest: None

\section{RESÚMEN}

Objetivo: identificar, baseados em critérios clínicos, um grupo de vítimas de trauma fechado com baixa probabilidade de apresentar alterações na radiografia simples de tórax à admissão (RXT).

Materiales y métodos: Análise retrospectiva dos dados de registro de trauma em um período de 24 meses entre 2008 e 2010. Foram selecionados adultos vítimas de trauma fechado que realizaram RXT à admissão. Avaliamos as seguintes variáveis clínicas: exame neurológico normal à admissão (ExNN), estabilidade hemodinâmica (EH), exame físico de tórax normal à admissão (ExTN), idade inferior a 60 anos (ID<60) e ausência de lesões distrativas (ALD) (AIS>2 cabeça, abdome, extremidades). Estes critérios clínicos foram progressivamente sobrepostos para selecionar um grupo com a menor probabilidade de apresentar uma RXT anormal à admissão.

Resultados: Foram incluídos 5536 vítimas de trauma fechado, sendo que $302(5,5 \%)$ apresentaram lesões torácicas. Dos 4647 que foram submetidos a RXT na admissão, 268 (5,7\%) apresentaram um achado anormal no exame. Dos 2897 admitidos com ExNN, 116 (4,0\%) tinham RXT alteradas. Dos 2426 com ExNN e EH, 74 (3,0\%) apresentaram alteração na RXT. Dos 1698 com ExNN, EH e ExTN, 24 (1,4\%) apresentaram RXT alterada. Dos 1347 com ExNN, EH, ExTN e ID<60, 19 $(1,4 \%)$ tinham RXT alterada. Doze dos 19 pacientes possuíam uma lesão torácica com AIS $>1$ confirmada $(0,9 \%$ do total de indivíduos que realizaram RXT). As lesões identificadas foram: fratura de costela (9), pneumotórax(3), hemotórax(1). Quatro pacientes necessitaram de drenagem torácica. Dos 1140 casos com ExNN, EH, ExTN, ID $<60$ e ALD, foram identificadas 9 $(0,8 \%)$ RXT alteradas, com 8 lesões torácicas confirmadas e dois casos que necessitaram de drenagem de tórax $(0,2 \%)$.

Conclusão: É possível identificar um subgrupo de vítimas de trauma fechado com baixa probabilidade de apresentar alterações à RXT à admissão. A necessidade da RXT neste subgrupo deve ser revista.

Palabras Clave: Diagnóstico, tórax, Radiografia, Trauma fechado, Trauma múltiplo.

\section{INTRODUCTION}

Trauma is the leading cause of death among persons aged 1 to 44 years worldwide. ${ }^{1}$ According to data from

This paper was presented in Resident Research Competition in PTS Annual Congress 2016, Maceio, Brazil 
the World Health Organization, 5.8 million people die from this cause annually. ${ }^{2}$ The National Safety Council estimated that, in 2007, the economic burden of trauma in the United States ${ }^{3}$ was approximately USD 684 billion, not including the estimated cost of lost productivity due to sequela. In Brazil, the DATASUS registered around 145,842 deaths due to external causes in $2011 .^{4}$ Thus, the magnitude of the problem and the need to provide effective and safe care for trauma patients are clear.

Thoracic injuries are often involved in trauma-related deaths. However, the majority of trauma patients have no serious injuries and can be managed using simple measures. ${ }^{5,6}$ To this end, much attention has been given to the type of complementary examination to be ordered. ${ }^{7,8}$ Currently, most services order routine chest radiography for blunt trauma patients as a supplementary scan to the physical examination, based on protocols, such as that of the Advanced Life Trauma Support (ATLS) course. $^{9,10}$

In the past decade, a series of studies have focused on determining the best radiologic examination to be ordered in chest trauma. ${ }^{11}$ Chest computed tomography (CT) has been proven to be superior for diagnosis, although therapeutic intervention was needed in approximately one-third of the diagnosed injuries. ${ }^{12}$ Other studies have also shown some benefits of chest CT over simple radiography in severe trauma, but the same correlation was not found for minor trauma. ${ }^{13,14}$

Concerns exist over the indiscriminate use of complementary examinations in trauma patients. This practice increases costs, exposure to radiation, and emergency department time. The number of negative examinations is directly associated with poor optimizing of resources. There is also a growing concern regarding the possible collateral effects of indiscriminate use of CT due to exposure to radiation, especially in the pediatric population. ${ }^{15-18}$ Thus, better ways of selecting patients to be submitted to complementary examinations are being sought.

In recent years, some authors have questioned the need for requesting chest X-rays (CXRs) in minor chest trauma. Prospective studies have been conducted showing favorable results. ${ }^{19-22}$ Optimizing the indication for CXRs can have a number of benefits. Conversely, the failure to identify severe chest injuries has clinically unfavorable consequences. There are arguments advocating systematic use of CXRs, given the examination is low cost and delivers a low dose of radiation. Nevertheless, clinical experience shows that most examinations performed are normal and do little to inform decisions on conduct.

The objective of the present study was to identify, using clinical criteria, a subgroup of blunt trauma patients that do not require CXR for assessment.

\section{MATERIALS AND METHODS}

This project was approved by the Research Ethics Committee of the hospital. We used the trauma registry database, collected prospectively for quality control between 2008 and 2010, which included all blunt trauma patients aged $>13$ years.

The following clinical variables on admission were analyzed: Age, trauma mechanism, physical examination of chest, Glasgow coma scale (GCS), and reliability of physical examination (level of preserved consciousness, no use of analgesics or drugs that change sensory level, absence of distracting injuries, and spinal cord trauma). The severity of injuries was stratified using the Abbreviated Injury Scale (AIS-90). ${ }^{23}$ Hemodynamic stability (HS) was defined as concomitant systolic arterial pressure $>100 \mathrm{~mm} \mathrm{Hg}$ and heart rate $<100 \mathrm{bpm}$.

Chest $\mathrm{X}$-rays were performed in front view, after the initial assessment. Both the chief resident and surgery staff on call reviewed the image to state the final result (normal or abnormal). Findings not related to the traumatic event, as well as those due to past traumas, were not considered for this decision.

We selected five clinical criteria that could be easily retrieved from the usual trauma assessment in order to estimate the patient's chance of sustaining chest injuries: Normal neurologic examination on admission (NNEx), HS, normal physical examination of the chest on admission (NCEx), age $\leq 60$ years, and absence of distracting injuries (AIS $>2$ in head, abdomen, and extremities).

These clinical criteria were progressively merged to select a group with lowest risk of exhibiting abnormal CXR on admission and absence of internal chest injuries, with AIS $>1$.

\section{RESULTS}

A total of 5,536 blunt trauma patients were analyzed. Of these patients, 302 (5.5\%) had chest injuries (AIS > 1) (Table 1). Of the 4,647 cases submitted to CXRs on admission, 268 (5.7\%) had abnormal findings on examination.

Among the 2,897 trauma patients scoring 15 on the GCS at admission and testing normal on NNEx, 116 (4.0\%) had abnormalities on CXRs.

Of the 2,426 patients with NNEx and HS, 74 (3.0\%) had positive CXRs. Among the 1,698 trauma patients that, besides the previous variables (NNEx and HS), also had no abnormalities on NCEx, only 24 (1.4\%) had abnormalities on CXR. From this group, a subgroup of individuals aged $\leq 60$ years was derived. Of the resultant 1,347 patients, 19 (1.4\%) had abnormal CXR. Out of 19 patients, 12 had confirmed thoracic injuries with AIS $>1$ ( $0.9 \%$ of all individuals that received CXR). Injuries were 
Table 1: Injuries identified in 4,674 patients that underwent CXR on admission

\begin{tabular}{lll}
\hline Injury & Number & Frequency (\%) \\
\hline Rib fracture & 158 & 3.38 \\
Pneumothorax & 91 & 1.95 \\
Pulmonary contusion & 86 & 1.84 \\
Hemothorax & 84 & 1.80 \\
Flail chest & 53 & 1.13 \\
Subcutaneous emphysema & 27 & 0.6 \\
Heart injury & 1 & 0.02 \\
Aorta injury & 4 & 0.08 \\
\hline
\end{tabular}

rib fracture (9), pneumothorax (3), and hemothorax (1). A total of 4 patients needed chest drainage.

Merging previous variables (NNEx, HS, NCEx, and age $<60$ ) with absence of distracting injuries (AIS $>2$ in head, abdomen, and extremities) yielded 1,140 cases. In this group, there were $9(0.8 \%)$ abnormal findings on CXR and 8 patients with confirmed thoracic injuries (Table 2): 2 pneumothorax and 6 rib fractures. Only $2(0.2 \%)$ cases required chest drainage.

\section{DISCUSSION}

Most studies confirm the low incidence of thoracic injuries in blunt trauma patients in general. ${ }^{19-22}$ In the present study, of the 4,647 cases that received CXR on admission, only $5.7 \%$ exhibited abnormalities on CXR. It is important to comment that the small percentage of chest injuries in our scenario may be related to the sample of the study. Due to the characteristics of local health system, our hospital receives many patients without serious injuries. So, optimizing the indication of complementary examinations is a key point in our reality.

The need to perform routine chest radiography in trauma, established in some trauma care protocols, such as the ATLS, has been questioned due to the high number of normal examinations and the costs associated with this practice in the emergency service..$^{15,24,25}$ Sears et $\mathrm{al}^{19}$ stated that, using the team's clinical judgment alone, around $50 \%$ of CXRs may not have been performed, saving approximately USD 100,000 in 12 months. In the present study, if we had opted not to perform the X-rays in the group of patients meeting all exclusion variables, 1,140 examinations would have been saved (47 examinations / month). The high rate of patients with blunt trauma for whom CRX was ordered and no injury disclosed reveals the need for reassessing the prevailing indication criteria.

Myint et $\mathrm{al}^{21}$ showed that the group of blunt chest trauma patients assessed as stable required no routine CXR, a result corroborated by the findings of the present study. Also a prospective study involving 386 cases, conducted by Nejati et al, ${ }^{20}$ compared the data collected on admission from patients (trauma mechanism, vital signs,
Table 2: Injuries identified and their treatment in 1,140 blunt trauma patients that met all clinical criteria (NNEx, HS, NCEx, age < 60 years and absence of distracting injuries) for low risk of thoracic injury

\begin{tabular}{llll}
\hline Injury & Number & Treatment & Frequency (\%) \\
\hline Rib fracture & 6 & 0 & 0.52 \\
Pneumothorax & 2 & 2 & 0.17 \\
Pulmonary contusion & 1 & 0 & 0.08 \\
\hline
\end{tabular}

oxygen saturation, auscultation, pain on palpation) with radiographic findings, showing that the combination of tachypnea and pain on palpation can identify significant chest trauma with $100 \%$ sensitivity. Our data revealed the association between normal findings on physical examination of the chest and absence of internal injuries.

Recently, the Nexus Chest study proposed a clinical decision instrument for determining the need for chest imaging, based on the absence of the following criteria: Chest pain, age $<14$ years and $>65$ years, intoxication, rapid deceleration mechanism, distracting injury, change in level of consciousness, and pain on chest wall palpation. This model allows the exclusion of thoracic injuries with $98.8 \%$ sensitivity, $98.5 \%$ negative predictive value, and $13.3 \%$ specificity. Of the 17 false negatives found, only 1 case required intervention ( 1 in 1,478 patients with injury seen on chest imaging). ${ }^{22}$ In the present casuistic, when all variables proposed were present, including $\mathrm{GCS}=15, \mathrm{NNEx}, \mathrm{HS}, \mathrm{NCEx}$, age $<60$ years, and absence of distracting injuries (AIS $>2$ head, abdomen, and extremities), there were 9 abnormal findings on CXR out of 1,140 cases $(0.9 \%)$. Of these 1,140 cases, only 2 required chest drainage $(0.2 \%)$.

Therefore, it proved possible to establish a subgroup of patients with blunt chest trauma and low risk of thoracic injury. The need for performing CXR in this group should be reassessed.

\section{CONCLUSION}

A subgroup of blunt trauma patients with low probability of exhibiting abnormalities on CXR at admission was identified. The need for routine CXR in this subgroup should be reviewed.

\section{REFERENCES}

1. American College of Surgeons Committee on Trauma. Advanced trauma life support (ATLS) Manual. Chicago, IL: American College of Surgeons; 2008.

2. World Health Organization. Global burden of disease. Switzerland: Update WHO Press; 2004.

3. National Safety Commission: Highlights from injury facts, 2009 Edition [cited 2009 Sept 4]. Available from: http://www. nsc.org.

4. Ministério da Saúde. DataSUS indicadores de mortalidade: óbitos por causa externa. [cited 2016 Feb 2]. Available from: http://tabnet.datasus.gov.br/cgi/deftohtm.exe?idb2011/c09.def. 
5. Martínez Casas I, Amador Marchante MA, Paduraru M, Olea AIF, Nolasco A, Medina JC. Thorax trauma severity score: is it reliable for patient's evaluation in a secondary level hospital? Bull Emerg Trauma 2016 Jul;4(3):150-155.

6. O'Connor JV, Adamski J. The diagnosis and treatment of non-cardiac thoracic trauma. J R Army Med Corps 2010 Mar;156(1):5-14.

7. Rodriguez RM, Hendey GW, Mower W, Kea B, Fortman J, Merchant G, Hoffman JR. Derivation of a decision instrument for selective chest radiography in blunt trauma. J Trauma 2011 Sep;71(3):549-553.

8. Wisbach GG, Sise MJ, Sack DI, Swanson SM, Sundquist SM, Paci GM, Kingdon KM, KaminskiSS. What is the role of chest $\mathrm{X}$-ray in the initial assessment of stable trauma patients? J Trauma 2007 Jan;62(1):74-79.

9. Rossen B, Laursen NO, Just S. Chest radiography after minor chest trauma. Acta Radiol 1987 Jan-Feb;28(1):53-54.

10. Mirvis SE, Bidwell JK, Buddemeyer EU, Diaconis JN, Pais SO, Whitley JE, Goldstein LD. Value of chest radiography in excluding traumatic aortic rupture. Radiology 1987 May;163(2):487-493.

11. Gavelli G, Canini R, Bertaccini P, Battista G, Bn C, Fattori R. Traumatic injuries: imaging of thoracic injuries. Eur Radiol 2002 Jun;12(6):1273-1294.

12. Langdorf MI, Medak AJ, Hendey GW, Nishijima DK, Mower WR, Raja AS, Baumann BM, Anglin DR, Anderson CL, Lotfipour S, et al. Prevalence and clinical import of thoracic injury identified by chest computed tomography but not chest radiography in blunt trauma: multicenter prospective cohort study. Ann Emerg Med 2015 Dec;66(6):589-600.

13. Omert L, Yeaney WW, Protetch J. Efficacy of thoracic computerized tomography in blunt chest trauma. Am Surg 2001 Jun;67(7):660-664.

14. Trupka A, Waydhas C, Hallfeldt KK, Nast-Kolb D, Pfeifer KJ, Schweiberer L. Value of thoracic computed tomography in the first assessment of severely injured patients with blunt chest trauma: results of a prospective study. J Trauma 1997 Sep;43(3):405-411.

15. Fazel R, Krumholz HM, Wang Y, Ross JS, Chen J, Ting HH, Shah ND, Nasir K, Einstein AJ, Nallamothu BK. Exposure to low-dose ionizing radiation from medical imaging procedures. N Engl J Med 2009 Aug;361(9):849-857.

16. Amis ES Jr, Butler PF, Applegate KE, Birnbaum SB, Brateman LF, Hevezi JM, Mettler FA, Morin RL, Pentecost MJ, Smith GG, et al. American College of Radiology white paper on radiation dose in medicine. J Am Coll Radiol 2007 May;4(5):272-284.

17. Berrington de González A, Mahesh M, Kim KP, Bhargavan M, Lewis R, Mettler F, Land C. Projected cancer risks from computed tomographic scans performed in the United States in 2007. Arch Intern Med 2009 Dec;169(22):2071-2077.

18. Markel TA, Kumar R, Koontz NA, Scherer LR, Applegate $\mathrm{KE}$. The utility of computed tomography as a screening tool for the evaluation of pediatric blunt chest trauma. J Trauma 2009 Jul;67(1):23-28.

19. Sears BW, Luchette FA, Esposito TJ, Dickson EL, Grant M, Santaniello JM, Jodlowski CR, Davis KA, Poulakidas SJ, Gamelli RL. Old fashion clinical judgment in the era of protocols: is mandatory chest $\mathrm{X}$-ray necessary in injured patients? J Trauma 2005;59(2):324-332.

20. Nejati A, Khalaj S, Azizkhani R, Shahryarian S, Kolahdouzan M, Hossein MS. Evaluating validity of clinical criteria for requesting chest $\mathrm{X}$-rays in trauma patients referred to emergency room. Adv Biomed Res 2012;1:22.

21. Myint KS, French S, Williams-Johnson J, Reid MO, GordonStrachan G. Role of routine chest radiographs in the evaluation of patients with stable blunt chest trauma a prospective analysis. West Indian Med J 2012 Jan;61(1):64-72.

22. Rodriguez RM, Anglin D, Langdorf MI, Baumann BM, Hendey GW, Bradley RN, et al. NEXUS chest: validation of a decision instrument for selective chest imaging in blunt trauma. JAMA Surg 2013 Oct;148(10):940-946.

23. Brohi K. Abbreviated Injury Scale (AIS) Score Overview of the anatomical scoring tool. London, UK. Published March 10, 2007 [cited 2016 Jan 04]. Available from: http://www. trauma.org/index.php/main/article/510/

24. Kool DR, Blickman JG. Advanced Trauma LifeSupport: ABCDE from a radiologic point of view. Emerg Radiol 2007 Jul;14(3):135-141.

25. Korley FK, Pham JC, Kirsch TD. Use of advanced radiology during visits to US emergency departments for injury-related conditions, 1998-2007. JAMA 2010 Oct;304(13):1465-1471. 


\section{Optimizing Chest X-ray Indication in Blunt Trauma Patients using Clinical Criteria}

The current paper nicely demonstrates that in a certain subgroup of trauma patients the chest $x$ ray can be omitted. In these patients careful physical exam and clinical judgment may suffice.

The authors are careful to point out that patients on whom chest $x$ ray is omitted need to exhibit a normal neurologic exam, hemodynamic stability, normal physical exam, age $<60$ years, and absence of distracting injuries.

As the authors point out, trauma accounts for a large economic burden in the United States, and the addition of complimentary radiologic exams such as "chest x-ray for all" no doubt contributes to this economic burden.

This reviewer congratulates the authors on a well written article which shows the potential safety of omitting routine chest $x$ rays for every last minor trauma simply because it is part of a protocol. It is papers like this that may give us pause to question our current practices. The practice should however be employed with caution - as in the author's series there were 8 patients with eight confirmed injuries that would have gone undiagnosed without a chest $x$ ray.

Rahul J Anand

Associate Professor of Surgery Program Director, Residency Program in General Surgery VCU Medical Center, Richmond, Virginia

\section{Optimizing Chest X-ray Indication in Blunt Trauma Patients using Clinical Criteria}

El siguiente artículo demuestra adecuadamente que en un cierto subgrupo de pacientes con lesiones por trauma se puede omitir la radiografía de tórax. En estos pacientes un examen físico y un juicio clínico cuidadoso pueden ser suficientes.

Los autores indican cuidadosamente que los pacientes a los que se ha omitido la radiografía de tórax, deben presentar; un examen neurológico normal, estabilidad hemodinámica, examen físico normal, edad <60 años y ausencia de lesiones distractoras.

Como señalan los autores, el trauma representa una gran carga económica en los Estados Unidos, y la adición de exámenes radiológicos complementarios como es una "radiografía de tórax para todos" sin duda contribuye a esta carga económica.

Este revisor felicita a los autores por un artículo bien escrito, que demuestra la seguridad potencial de omitir radiografías de tórax rutinarias para cada trauma menor simplemente porque es parte de un protocolo. Son artículos como éste los que nos permiten hacer una pausa para cuestionar nuestras prácticas actuales. Sin embargo, dicha práctica debe emplearse con precaución, ya que en la serie del autor había 8 pacientes con ocho lesiones confirmadas que no hubiesen sido diagnosticadas sin una radiografía de tórax.

Rahul J Anand

Associate Professor of Surgery

Program Director, Residency Program in General Surgery VCU Medical Center, Richmond, Virginia 